PALABRAS ClAVE
Comercio internacional
Multilateralismo
Competencia
Política comercial
omc
Proteccionismo
Regulación económica
Cooperación regional
Mercados emergentes
América Latina
Brasil
China
Rusia
India

Osvaldo Rosales V.

Director,

División de Comercio Internacional e Integración

CEPAL

osvaldo.rosales@ cepal.org
REVISTA CEPAL 97 - ABRIL 2009

\section{La globalización y los nuevos escenarios del comercio internacional}

\author{
Osvaldo Rosales $V$.
}

L

economía global se caracteriza por la intensidad del cambio tecnológico y el surgimiento de competidores poderosos como China y los demás países BRIC, lo que se ha traducido en drásticos cambios en la competitividad y una tendencia a estructurar la producción en torno a cadenas mundiales de valor. En ese contexto, se han reactivado las amenazas tradicionales de proteccionismo y han aparecido otras vinculadas a las nuevas exigencias en materia de seguridad, las normas privadas de calidad, las buenas prácticas y el cambio climático. Se trata de ámbitos inherentes a la nueva competitividad, pero que sin un enfoque multilateral adecuado pueden transformarse en barreras proteccionistas. Sobre esa base, y dado el actual escenario de crisis global, se proponen algunas políticas orientadas a adoptar una estrategia de internacionalización en los países de la región, haciendo hincapié en la importancia de la innovación y en los temas que pueden abordarse desde una óptica de cooperación regional. 


\section{I}

\section{Introducción}

Durante las tres últimas décadas, en la economía internacional se ha registrado un intenso proceso de transición caracterizado por el avance de la globalización, la intensidad del cambio tecnológico y el surgimiento de competidores nuevos y destacados como China, la India y, en general, Asia-Pacífico. Las implicancias de esta tríada son variadas y complejas e incluyen, por ejemplo, drásticos cambios en el mapa mundial del intercambio comercial y las ventajas competitivas, así como nuevos ganadores y perdedores a nivel de zonas económicas, países, sectores productivos y empresas. La magnitud de estas transformaciones podría conducir incluso a algunos ajustes del enfoque "centro-periferia", toda vez que - al menos en sus versiones menos refinadas- no permite explicar la creciente presencia de países en desarrollo competitivos que incursionan en los segmentos dinámicos de la economía mundial y son portadores del cambio tecnológico.

La contracción del crecimiento económico mundial observado hasta la fecha habría sido mucho más severa de no ser por la pujanza de grandes mercados emergentes como los del llamado grupo de los BRIC, integrado por el Brasil, China, la Federación de Rusia y la India, al menos hasta el primer semestre de 2008. En la actualidad, estos países y las economías emergentes en general representan el grueso del crecimiento del producto interno bruto (PIB) mundial y una porción significativa del comercio internacional. El protagonismo de los países BRIC también se aprecia en el ámbito financiero, puesto que desempeñan un papel cada vez más importante en la mantención de los equilibrios económicos globales. Cualquier indicio de lo que estos — sobre todo Chinapodrían hacer con sus enormes reservas tiene inmediatas repercusiones en los mercados financieros mundiales. Por otra parte, cualquier solución de la crisis, que sea sustentable a largo plazo, debería incluir un mayor espacio en la gobernabilidad financiera internacional a los BRIC y a las economías emergentes.

Uno de los rasgos destacados de la globalización es que las corrientes financieras superan con mucho, en velocidad y volumen, a los flujos reales de la economía. Esta marcada disparidad, sin embargo, oculta el hecho de que las transformaciones que están teniendo lugar en la producción y el comercio mundial son igualmente espectaculares y decisivas en las perspectivas de creci- miento de los próximos años. Es en estas últimas que se centrará la atención del presente artículo. Las severas repercusiones de la actual crisis financiera global no menoscaban la validez de estos temas. En efecto, el principal costo que ella podría tener para América Latina y el Caribe sería el de repetir los errores que se cometieron mediante las políticas de ajuste de los años ochenta, afectando innecesariamente el crecimiento y el empleo y, más que nada, sacrificando la inversión en infraestructura, educación e innovación. Son esos costos los que explican el aumento de la brecha entre la región y las economías de Asia-Pacífico.

Pese a la magnitud de los cambios registrados en la economía mundial, que coincidieron con un ciclo expansivo notable (2003-2007), no se ha logrado desterrar los peligros del proteccionismo tradicional —en la agricultura, los subsidios a la exportación y los apoyos directos internos, así como el antidumping, entre los más importantes-, mientras que la incertidumbre vinculada al nuevo escenario internacional dificulta los avances en las negociaciones multilaterales de comercio y abre espacios para la aplicación de medidas proteccionistas. Si la economía mundial se contrae en los años 2009 y 2010, no solo se obstaculizará la Ronda de Doha. En un contexto de desaceleración económica y de contracción crediticia en las economías industrializadas, los desafíos competitivos que plantean las economías emergentes pueden activar las presiones en favor de renovadas formas de proteccionismo. Hay temas nuevos de la agenda global tales como la seguridad en el comercio, los vínculos entre comercio, cambio climático y medio ambiente e incluso algunos aspectos inherentes a la competitividad como la certificación de calidad o las buenas prácticas productivas que, de ser mal manejados, podrían acentuar esas tendencias, afectando de preferencia a las exportaciones de recursos naturales y de manufacturas basadas en los recursos naturales.

La relevancia creciente de la innovación y las perspectivas de un escenario internacional menos dinámico subrayan la necesidad de aplicar políticas de internacionalización que, focalizadas en aumentar el conocimiento incorporado en las exportaciones, contribuyan a estimular las alianzas internacionales, la articulación de redes comerciales internacionales, una mayor presencia en las cadenas globales de valor, las 
inversiones en el exterior, el apoyo de las pequeñas y medianas empresas (pymes) centrado en el acceso a los aspectos intangibles de la nueva competitividad y, en fin, una apuesta más sustantiva por la formación de recursos humanos que sea compatible con la magnitud del intenso cambio tecnológico que nos ha tocado vivir.

\section{II}

\section{La incertidumbre en el escenario multilateral del comercio}

Para abordar los nuevos desafíos globales, es apremiante modificar la institucionalidad y accionar de la Organización Mundial del Comercio (OMC). Sin embargo, primero habría que concluir la Ronda de Doha, entre otras cosas porque el fracaso de ella reduciría el espacio para efectuar una reforma significativa de la omc.

\section{La necesidad de concluir la Ronda de Doha}

Dada la gravedad del escenario internacional en que derivó la crisis subprime, han surgido voces que aconsejan archivar la Ronda de Doha para el Desarrollo hasta un momento más propicio. Esta es la peor sugerencia posible. Al contrario, precisamente porque la crisis es tan severa sería necesario concluir cuanto antes el proceso de negociaciones, procurando por supuesto que los resultados sean balanceados y que respondan al objetivo declarado de ser un aporte para el desarrollo. La necesidad urgente de cerrar la Ronda de Doha crece en forma proporcional al empeoramiento de los pronósticos sobre la evolución de la economía y el comercio mundiales durante 2009 y 2010.

Esperar mejores tiempos para retomar las negociaciones de la Ronda de Doha sería particularmente desacertado debido, cuando menos, a dos razones. Por una parte, el hecho de que este proceso haya coincidido con el ciclo más favorable de la economía mundial en los últimos 40 años (2003-2007) y que en ese lapso no fuera posible lograr avances significativos. Por otra, el mensaje enviado al suspender las negociaciones explícitamente en espera de una mejor coyuntura contribuiría a agravar aún más las perspectivas de la economía mundial, puesto que abrirá espacios no solo para aplicar medidas que bloqueen en forma directa el comercio, sino también otras que, con el pretexto de apoyar a los sectores afectados por la crisis, terminen generando nuevas disputas sectoriales que recargarán el ámbito de solución de controversias de la OMC, sin permitirle avanzar en el área de las negociaciones comerciales. Esto le conviene poco a la Organización, pues la aleja del campo de los acuerdos y la focaliza en el de los conflictos.

La actual crisis económica internacional, la más severa que se haya registrado en casi 80 años, constituye el principal desafío respecto de los avances recientes en materia de liberalización comercial, sobre todo porque las dos fuerzas motrices de la globalización —el comercio y las corrientes de capital- se encontrarán en receso durante 2009 y parte de 2010. Las amenazas de proteccionismo aparecen entonces como un problema extremadamente delicado del futuro inmediato. En un escenario de contracción económica simultánea en los Estados Unidos, la Unión Europea (UE) y Japón, caracterizado por el aumento del desempleo y las dificultades para acceder al crédito, a las autoridades políticas les será difícil resistir las presiones en favor de los subsidios y las trabas al comercio. El debate sobre el millonario apoyo a la industria automotriz estadounidense ilustra los peligros mencionados. Si otros socios siguieran el mismo camino, se desplazaría el escenario de competitividad desde la calidad y los bajos costos hacia la capacidad presupuestaria de los gobiernos. Este tipo de salvatajes sectoriales puede tener graves efectos en el comercio internacional, dado que es la industria global la que se está viendo sometida a una drástica caída de la demanda y los programas especiales de respaldo financiero favorecen solo a algunos de sus segmentos. En un marco de demanda global, que continúa resintiéndose, los programas de apoyo podrían dar lugar a ventajas competitivas artificiales que obedecen exclusivamente a diversas modalidades de ayuda fiscal.

El peligro proteccionista no solo radica en las medidas que podrían contravenir los compromisos de la OMC. Luego de dos décadas de rebajas unilaterales, los aranceles que se aplican en la práctica son bastante inferiores a los techos máximos consolidados en la Organización. De hecho, los países podrían duplicar 
los aranceles actuales sin violar dichos compromisos, con lo cual el comercio internacional se contraería un 8\% (The Economist, 2008a). Esto es exactamente lo que se necesita para que la crisis actual se convierta en una depresión de proporciones históricas. Si algo se aprendió de la situación de los años treinta fue que las políticas procíclicas y el proteccionismo contribuyeron a profundizar y alargar el problema. Hasta ahora el discurso parece ir bien encaminado, según lo demostró la reunión del Grupo de los Veinte (G-20) realizada en noviembre de 2008, en Washington, D.C. Sin embargo, si se examina el estado de cumplimiento de los tres principales compromisos, queda poco espacio para el optimismo. ${ }^{1}$

\section{Las reformas de la Organización Mundial del Comercio}

Entre las principales reformas de la OMC se han mencionado las siguientes: i) abordar la erosión de los principios básicos de no discriminación (tratamiento de nación más favorecida y trato nacional) a que ha dado lugar la proliferación de convenios preferenciales de comercio o acuerdos de libre comercio; ii) mejorar el trato especial y diferenciado en favor de los países en desarrollo, particularmente de aquellos de menor desarrollo relativo; iii) mayor coordinación entre la Organización y las agencias multilaterales de financiamiento, a fin de acompañar las reformas comerciales con asistencia financiera a los países en desarrollo; iv) crear mecanismos institucionales que permitan una toma más rápida y eficaz de decisiones, y v) reforzar los vínculos entre la OMC y las organizaciones de la sociedad civil (OMC, 2004).

\section{a) Conservar la no discriminación}

Uno de los rasgos destacados del escenario internacional es la proliferación de acuerdos de libre comercio de carácter bilateral o plurilateral cuyos beneficios, por definición, se limitan exclusivamente a sus signatarios. Ellos contravienen los principios de no discriminación establecidos tanto en virtud del tratamiento de nación más favorecida, que obliga a los miembros de la OMC a otorgar un trato similar a todos

\footnotetext{
${ }^{1} \mathrm{Al}$ parecer, en ninguna de estas 20 economías se ha concretado el compromiso de aplicar una política fiscal anticíclica y un programa de gasto adicional equivalente a un máximo del $2 \%$ del PIB; el de concluir la Ronda de Doha en 2008 fracasó, mientras que el de no imponer nuevas barreras comerciales durante 12 meses ya lo quebrantaron varios de los gobiernos participantes de esa reunión.
}

los interlocutores comerciales, como del trato nacional que, en determinadas materias, exige dar a dichos socios el mismo trato que a los actores económicos nacionales. Este tipo de convenios se han posibilitado gracias al artículo XXIV del Acuerdo General sobre Aranceles Aduaneros y Comercio (GATT), que permitió la existencia de uniones aduaneras y acuerdos de libre comercio, aunque sujetos a ciertas condiciones. ${ }^{2}$ Hasta ahora, la interpretación de estas últimas permanece en el campo de la ambigüedad y no se ha detectado mayor interés de los países por definirlas en forma más precisa a fin de comprobar en qué medida la malla de acuerdos preferenciales se ajusta a las exigencias del GATT, hoy OMC.

Dada esa proliferación de acuerdos de libre comercio, nos adentramos en un mundo en que el tratamiento de nación más favorecida que hace dos décadas era la norma pase a ser la excepción, debilitando severamente a la Organización Mundial del Comercio, puesto que el grueso de las corrientes comerciales se regiría de acuerdo con disciplinas que - aunque similares- no dependerían de ella. Los países signatarios de este tipo de convenios deben informar de ellos a la OMC, pero se trata de un trámite meramente formal y la Organización no cuenta con mecanismos eficaces para evaluar sus efectos internos y sus repercusiones en otros socios. ${ }^{3}$ Desde este punto de vista, podría ser más atractivo que se abocara a estudiar la posibilidad de mejorar los vínculos entre los distintos acuerdos, a fin de que constituyan realmente un elemento positivo (building block) para el libre comercio y no un obstáculo (stumbling block), esto es, utilizar los acuerdos preferenciales para avanzar hacia la multilateralización de los compromisos y evitar que se conviertan en una fortaleza que impide el intercambio con otros socios que no pertenecen a ellos.

\footnotetext{
2 Básicamente, se trata de las siguientes condiciones: i) que la constitución de estas agrupaciones no se traduzca en barreras arancelarias o regulaciones comerciales más restrictivas, tanto entre los miembros de una determinada unión aduanera o zona de libre comercio como respecto de terceros países no integrantes de ellas y ii) que los acuerdos comerciales originados a partir de esas uniones aduaneras o zonas de libre comercio permitan eliminar en lo esencial los obstáculos al intercambio comercial entre los países signatarios.

${ }^{3}$ Se ha sugerido incorporar este aspecto en el Mecanismo de Examen de las Políticas Comerciales, dotando a la oMC de mayores facultades para evaluar el aporte real de los acuerdos de libre comercio a la liberalización de las corrientes comerciales. Sin embargo, ello implicaría atender la agenda comercial relevante en su conjunto - tanto los temas viejos como los nuevos-, pues solo así se reduciría el incentivo a suscribir ese tipo de convenios. Pero esta posibilidad se ve lejana y todo indica que en los próximos años persistirá la tendencia a concertar acuerdos de libre comercio.
} 
b) Mejorar las disposiciones en materia de trato especial y diferenciado

Los mecanismos tradicionales han consistido, por una parte, en otorgar mayor plazo para cumplir los compromisos a los países en desarrollo de menor desarrollo relativo y, por otra, en la posibilidad de que un conjunto significativo de sus productos pueda ingresar al mercado de los principales países o agrupaciones en condiciones de liberación total o parcial del pago de aranceles. El análisis del grupo de expertos convocado por la OMC concluyó que estas modalidades eran insuficientes y, algunas de ellas, incluso inconducentes. En efecto, se estimó que el Sistema Generalizado de Preferencias (SGP) que aplican, por ejemplo, los Estados Unidos y la UE en el caso de las exportaciones de los países en desarrollo termina siendo ineficaz por las siguientes razones: i) como se trata de beneficios concesionales y no vinculantes, no son estables ni permiten emprender planes de inversión conexos a largo plazo; ii) en algunas ocasiones, las preferencias se vinculan a obligaciones que no están relacionadas con el comercio; iii) los beneficios tienden a favorecer más a quien otorga las concesiones, lo que se deduce de la cantidad de productos abarcados y de los márgenes de preferencia otorgados; iv) el techo de los beneficios suele ser reducido, puesto que las preferencias se modifican arbitrariamente en función de la mayor competitividad que va adquiriendo el producto beneficiado; y v) existe una tendencia por parte de los países beneficiarios a apoyarse de manera excesiva en estas preferencias, limitando sus esfuerzos por diversificar las exportaciones (OMC, 2004).

Es posible replantear entonces el concepto de tratamiento especial y diferenciado, vinculándolo en mayor medida a las temáticas de ayuda para el comercio y de facilitación de este, proveyendo a los países en desarrollo de recursos que les permitan mejorar y ampliar su infraestructura, su oferta exportable, la formación de recursos humanos y la capacitación de sus trabajadores, así como la agrupación de sus pymes y el acceso de estas al crédito y a las nuevas tecnologías. Ello requiere de una relación más estrecha y funcional entre la OMC y las agencias multilaterales de financiamiento como el Banco Mundial y los bancos regionales, a fin de contar con recursos que permitan acompañar las reformas comerciales con los complementos necesarios en materia de infraestructura, recursos humanos y tecnologías. Los acuerdos comerciales, sea discriminatorios o no, generan solamente oportunidades potenciales de aumento de la demanda que solo pueden aprovecharse si se cuenta con la oferta exportable pertinente. Esta necesidad de ampliar y diversificar la oferta exportable es aún mayor en los países en desarrollo de menor desarrollo relativo. Dicho en breve, el énfasis de la renovación del tratamiento especial y diferenciado debería desplazarse desde la demanda hacia la oferta de exportaciones.

\section{c) Mejorar el funcionamiento de la OMC}

Otro tema de debate es el procedimiento de toma de decisiones de la Organización Mundial del Comercio, ya que estas se adoptan por consenso y no por votación. Por cierto, hay pros y contras en cada una de estas opciones, ${ }^{4}$ pero lo que hoy se está discutiendo es la necesidad de contar con mecanismos más ágiles y reuniones ministeriales más eficientes, así como reforzar la participación política de alto nivel. Al respecto, se han examinado modalidades de "geometría variable" que permitirían circunscribir los compromisos a quienes respalden inicialmente las decisiones, sin perjuicio de irlos multilateralizando a medida que se vayan incorporando nuevos socios.

Otra inquietud es la de seguir avanzando en las normas sobre transparencia y de mejorar los vínculos con las organizaciones de la sociedad civil, difundiendo más activamente las funciones y acciones de la OMC, capacitando y ofreciendo asistencia técnica sobre las normativas comerciales a gobiernos, academia, organizaciones empresariales y medios de comunicación. $\mathrm{Al}$ respecto, el mecanismo de solución de controversias —uno de los más prestigiados de la Organización— es uno de los pocos espacios multilaterales en que las quejas de los países en desarrollo no solo han encontrado eco, sino que en muchos casos han conducido a la modificación de las políticas de los países industrializados que ellos cuestionaron. ${ }^{5}$

El principal aporte de la OMC al fortalecimiento de la economía mundial consiste en un conjunto de disciplinas comerciales que garantizan la utilización de reglas del juego previsibles y que evitan los retrocesos en épocas de crisis o contracción/desaceleración económica como la que se está viviendo en la actualidad. En ausencia de iniciativas de reactivación de la Ronda de Doha, convendría realizar mayores esfuerzos por detectar y difundir las consecuencias de la crisis financiera en el comercio, registrando las medidas de protección que los miembros de la Organización están aplicando al respecto, sea que

\footnotetext{
${ }^{4}$ Para una discusión más detallada al respecto, véase omc (2004).

${ }^{5}$ Para una visión de conjunto de las controversias en la OMC, es posible consultar la Base de datos integrada de controversias comerciales de América Latina y el Caribe (BADICC), preparada por la División de Comercio Internacional e Integración de la CEPAL [en línea] http:// badicc.eclac.cl o http://www.cepal.org/comercio.
} 
cumplan o no con la normativa vigente. Asimismo, sería importante documentar el monto de recursos involucrado y los costos que ellas representan para los países en desarrollo. Algo parecido podría hacerse en relación con el costo de las medidas proteccionistas que estos mismos países utilizan y sus efectos distributivos que, normalmente, afectan en mayor medida a los grupos de menores ingresos. Ello sería un esfuerzo pedagógico de alerta internacional sobre los rumbos que va tomando el comercio y contribuiría a sensibilizar a los miembros de la OMC sobre la necesidad de retomar las negociaciones de la Ronda de Doha.

\section{III}

\section{Las nuevas amenazas de}

\section{proteccionismo en el siglo XXI}

La acelerada dinámica del cambio tecnológico y sus repercusiones en la jerarquía competitiva de empresas, conglomerados y naciones tiende a manifestarse también en la definición de nuevos temas comerciales que inciden en la competitividad, aunque muchos de ellos no hayan sido abordados aún en la normativa multilateral del comercio.

Las normas sobre seguridad comercial que promueven unilateralmente algunos países, o que son recomendadas por organismos multilaterales como la Organización Mundial de Aduanas (OMA), se traducen en fuertes presiones para realizar mejoras institucionales y de operación en toda la cadena de actividades comerciales. En este ámbito, se han impulsado normas privadas que son de aplicación voluntaria, pero que pueden afectar las condiciones de competitividad de los países. Destacan entre ellas las buenas prácticas agrícolas, las certificaciones de inocuidad, las normas de la Organización Internacional de Normalización (ISO) y las certificaciones de calidad. También ha crecido la influencia de los movimientos ambientalistas y de consumidores, particularmente en Europa, lo que provoca efectos indirectos en el comercio internacional al elevar el nivel de exigencias en materia de inocuidad y "trazabilidad" de los productos alimenticios en los mercados de los países industrializados. Por último, cabe mencionar el tema de los efectos ambientales y climáticos del crecimiento económico y del comercio internacional.

Se aprecia, pues, un marcado rezago del sistema de comercio multilateral en comparación con la intensidad del cambio tecnológico y frente a las iniciativas unilaterales respaldadas normalmente por la nueva estructura de actores empresariales que, en muchas ocasiones, tiene mayor incidencia en los temas comerciales que los propios gobiernos de los países industrializados. Esta interacción —que podríamos simplificar como desarrollo tecnológico y empresarial, por una parte, e incorporación de nuevos temas e instituciones, por otra- es muy compleja, ya que combina los requisitos que surgen a partir del avance tecnológico, como la certificación de calidad y los modelos de negocio basados en el cambio tecnológico que pretenden limitar la competencia y proteger las actividades privadas, tal como ocurre con ciertas exigencias de certificación vinculadas a laboratorios y empresas específicos.

Los límites entre el avance tecnológico, los nuevos temas, la creación de nuevas agencias e instituciones y el proteccionismo son muy sutiles y pueden traspasarse con facilidad, particularmente si los países en desarrollo no cuentan con una capacidad técnica que les permita diferenciar los cambios propios de la modernidad, a los cuales habría que adecuarse, de aquellos que no corresponden más que a formas novedosas de negocios privados que pueden obstaculizar la competencia o estimular el proteccionismo.

\section{La seguridad en el comercio internacional}

Tras los atentados del 11 de septiembre de 2001, las normas de seguridad pasaron a ocupar un lugar más relevante en las relaciones internacionales, afectando el marco normativo del comercio debido, en particular, a la necesidad de evitar que la cadena mundial de suministro de bienes se utilizara con fines terroristas. Esto condujo a la creación de la Asociación aduanera y comercial contra el terrorismo (C-TPAT) en los Estados Unidos (2002), del programa de Operador Económico Autorizado (OEA) de la Organización Mundial de Aduanas (2005) y del programa Socios para la Protección del Canadá, iniciativas orientadas a asegurar los canales de 
aprovisionamiento. ${ }^{6}$ Los nuevos programas de seguridad en el comercio van más allá del producto y consideran el correcto tratamiento y rastreabilidad de la carga a lo largo de toda la cadena de suministro, basándose en el concepto de que "la seguridad de la cadena de transporte es siempre igual a la del eslabón más débil" (Comisión de las Comunidades Europeas, 2003).

El cumplimiento de las nuevas exigencias se traduce en nuevos costos; más aún, ellas varían de acuerdo con la situación previa de la empresa y el nivel de certificación solicitado. ${ }^{7}$ Estas medidas pueden afectar adversamente a los pequeños y medianos productores, puesto que si no logran cumplir con los requisitos de los programas citados, se arriesgan a perder mercados por falta de competitividad frente a quienes ya lo hacen y cuyas mercaderías ingresan no solo en forma más rápida, sino con mayores garantías de seguridad. Así, la competitividad de los productos ya no radica únicamente en calidad y precio, sino también en la seguridad, variable cuyo peso en relación con el acceso a los mercados más sofisticados podría aumentar.

\section{Las normas privadas que regulan la calidad e inocuidad de los alimentos}

Existe una preocupación creciente por la inocuidad de los alimentos y por la posible contaminación accidental de los mismos. Una de las consecuencias de la globalización de las cadenas agroalimentarias es que se van integrando eslabones productivos que responden a diversos estándares institucionales nacionales, incluidas la calidad de la regulación sanitaria y fitosanitaria, la protección transfronteriza e incluso la eficiencia y honradez funcionarias. Si bien en las últimas décadas la inocuidad de los alimentos ha mejorado de manera espectacular, los avances a nivel de países son irregulares, de manera que persisten importantes brotes de enfermedades transmitidas por alimentos contaminados por microorganismos, sustancias químicas o toxinas. De este modo, el comercio transfronterizo de alimentos contaminados puede contribuir a la propagación de tales brotes (OMs, 2007).

Los estándares voluntarios de calidad han aumentado tanto en cantidad como en nivel de exigencias, con miras

\footnotetext{
${ }^{6}$ Para mayores detalles sobre estas iniciativas, véase CEPAL (2008a, cap. III).

${ }^{7}$ Esto abarca, por ejemplo, medidas de seguridad física en la empresa, protección de la carga, procedimientos de seguridad del personal, sistemas de identificación y de monitoreo del personal y sistemas de comunicación electrónica y de base de datos.
}

a lograr la inocuidad de los productos y el compromiso empresarial con la protección ambiental y los derechos laborales, entre otros. Varias instituciones públicas y privadas que velan por la inocuidad y la sostenibilidad de la producción promueven conceptos y programas de buenas prácticas agrícolas y de manufactura, junto con los distintos actores de la cadena agroalimentaria. ${ }^{8}$

Por otra parte, en los últimos años han surgido organizaciones que promueven el concepto de "comercio justo" y la certificación privada, esto es, la emisión de sellos que garantizan que un determinado producto se elaboró de conformidad con ciertos criterios que ellas mismas han definido. En la actualidad, existen 20 iniciativas de comercio justo certificado, que pertenecen principalmente a países de Europa y América del Norte y cuyo objetivo es regular el uso del sello de certificación de los productos. ${ }^{9}$

Se sabe que para participar en las cadenas globales de valor es preciso satisfacer los estándares internacionales de calidad. En este sentido, el cumplimiento de las normas privadas y voluntarias pertinentes puede facilitar el acceso a los segmentos más rentables de esas cadenas. Sin embargo, en algunas ocasiones el concepto de "comercio justo" puede lindar peligrosamente con las tentaciones proteccionistas, sobre todo cuando se busca imponer prácticas empresariales bastante específicas originadas en las economías industrializadas y que no son necesariamente superiores a las que puedan haber surgido en los países en desarrollo. Por otra parte, restringe bastante el hecho de que en las prácticas de comercio desleal (unfair trade) no se haga suficiente hincapié en denunciar el proteccionismo agrícola de las economías industrializadas. En otros casos, la propia certificación de calidad puede convertirse en un atractivo negocio, desligándose hasta cierto punto del objetivo inicial de contribuir al predominio de buena calidad en toda la cadena de valor. Debido a la proliferación de normas privadas y a su creciente exigencia en los mercados, particularmente en el sector alimentario, los exportadores deben acudir a un mercado de certificaciones de calidad

\footnotetext{
${ }^{8}$ Las "buenas prácticas agrícolas" son las medidas que se aplican en el ámbito de la producción, procesamiento y transporte de productos de origen agropecuario a fin de asegurar la inocuidad de los productos y la protección del medio ambiente y del personal que trabaja en su explotación.

${ }^{9}$ Estas iniciativas se agrupan en la Fairtrade Labelling Organizations International (FLO), asociación que proporciona apoyo directo a los productores certificados, definiendo los criterios de lo que considera "comercio justo". Sobre la base de las normas Iso para organismos de certificación, la FLo inspecciona y certifica a unas 500 organizaciones de productores en más de 50 países de África, América Latina y Asia.
} 
poco transparente, con marcadas barreras de entrada y con cierto grado de conflicto de intereses entre estas agencias y los principales productores de las economías centrales. En este sentido, no deja de ser preocupante que en los mercados internacionales tiendan a imponerse unas normas que comenzaron siendo privadas y voluntarias y que se originaron en grandes consorcios mundiales, bien por su gradual multilateralización de facto, su gran incidencia en los mercados clave o el carácter oligopólico de las agencias de certificación.

En algunos casos, los gobiernos adoptan total o parcialmente las exigencias de calidad del sector privado y buscan normalizar el tema, con lo cual, en la práctica, estos requerimientos pueden tornarse obligatorios. De esta manera, el sector agropecuario, y sobre todo el agroexportador, se ve obligado a adaptarse a una gran cantidad de exigencias tanto públicas como privadas (Salles de Almeida, 2008). ${ }^{10}$

\section{Los efectos comerciales de la implementación de estándares privados}

La adopción de los estándares privados —además de las normas oficiales de aplicación obligatoria- constituye un desafío y una oportunidad para los países de la región, ya que su cumplimiento puede convertirse en un requisito de hecho para exportar productos agropecuarios a mercados de mayor conciencia ambiental y crecientes exigencias de calidad. Si bien es posible que la observancia de este

\footnotetext{
${ }^{10}$ Entre las más relevantes se cuentan las normas ISo, de producción orgánica, de inocuidad, de buenas prácticas, de denominación de origen y las indicaciones geográficas.
}

tipo de normas favorezca las oportunidades de acceso a los mercados exigentes, ellas también pueden conformar una barrera comercial si se considera el costo que representan, sobre todo para los proveedores de los países en desarrollo. Asimismo, podrían esconder una intención proteccionista si las exigencias pertinentes exceden los requisitos establecidos en el Acuerdo sobre la Aplicación de Medidas Sanitarias y Fitosanitarias (Acuerdo MSF) de la Organización Mundial del Comercio. En general, los exportadores agropecuarios de los países en desarrollo sienten inquietud ante la proliferación de normas privadas. $\mathrm{Al}$ respecto, la OMC distingue entre las preocupaciones comerciales relacionadas con el contenido y las relativas al cumplimiento de ellas (véase el cuadro 1).

Las principales inquietudes que se han planteado ante la OMC se refieren a la relación entre las organizaciones privadas y las instituciones internacionales de normalización —en general, las normas privadas son más rígidas que los estándares internacionales-; al carácter innecesario de algunas restricciones al comercio impuestas por las normas privadas, sobre todo para los pequeños agricultores; a las medidas que podrían adoptar los gobiernos para asegurar que las organizaciones privadas cumplan con el Acuerdo MSF, y a su relación con otras esferas de trabajo de la omc, tales como los obstáculos técnicos al comercio. También preocupa la falta de transparencia de las normas del sector privado, considerando que estas no se notifican a la OMC.

En lo que respecta a las buenas prácticas agrícolas, los países en desarrollo enfrentan tres importantes desafíos: i) garantizar que incluyan los intereses de los pequeños productores tanto en materia de inocuidad de los productos como de sostenibilidad de la producción interna, ya que los criterios demasiado exigentes

CUADRO 1

\section{Preocupaciones relativas a la aplicación de normas sanitarias y fitosanitarias privadas}

Relacionadas con el contenido

Multiplicación de los sistemas de normas privadas dentro y entre los mercados.

Imprecisión de la frontera entre las normas sanitarias y fitosanitarias oficiales y las privadas.

Relación entre los sistemas privados y las instituciones internacionales de normalización mencionadas en el Acuerdo sobre la Aplicación de Medidas Sanitarias y Fitosanitarias.

Justificación científica de algunas prescripciones en materia de procesos y métodos de producción.
Relacionadas con el cumplimiento

Costo de la certificación por parte de terceros, en particular para las pequeñas y medianas empresas y los agricultores de los países en desarrollo.

Exigencia de algunos sistemas privados de recurrir únicamente a determinados organismos de certificación.

Falta de equivalencia entre los sistemas que da lugar a la repetición de las auditorías de certificación.

Falta de reconocimiento de los certificados emitidos o ausencia de organismos de certificación acreditados en los países en desarrollo.

Fuente: Organización Mundial del Comercio (OMC), Las normas privadas y el Acuerdo MSF (G/sps/GEN/746), Comité de Medidas Sanitarias y Fitosanitarias, Ginebra, 24 de enero de 2007. 
podrían desalojar a los pequeños productores; ii) evitar una sobrecarga de prácticas y reglamentos que si bien no son jurídicamente vinculantes, en la práctica determinan el acceso a los mercados, y iii) vigilar sus efectos en los costos de producción, la certificación y la comercialización, sobre todo entre los productores de menor tamaño.

\section{Las implicaciones del cambio climático en el sistema de comercio}

El cambio climático será uno de los desafíos más importantes que enfrentará la comunidad internacional en los próximos años. El sistema de comercio es un foco de tensión, dados los conflictos potenciales entre el cambio climático y los principios básicos del comercio internacional — no discriminación, eliminación de restricciones cuantitativas y discriminación no arbitraria_- Para cumplir con las obligaciones internacionales en esta materia, sobre todo en el marco del Protocolo de Kyoto, los gobiernos han comenzado a redactar disposiciones legales específicas. Si dicha legislación no toma en cuenta los principios básicos de la OMC, es probable que los miembros procuren zanjar sus diferencias mediante el mecanismo de solución de controversias, lo que aumentaría el costo de la cooperación e intensificaría la oposición respecto del funcionamiento del sistema multilateral basado en las normas de la Organización (Hufbauer, 2008).

En los países desarrollados han surgido distintas iniciativas para abordar el vínculo entre cambio climático y comercio, mediante la implementación de "medidas de ajuste en la frontera" (Brewer, 2007). En 2007 y 2008, en los Estados Unidos y la Unión Europea se discutieron diversas propuestas legislativas a nivel nacional para enfrentar estos temas. El abanico de iniciativas abarca desde la posible aplicación de sobretasas arancelarias en función de la contribución de toda la cadena de suministro de cada producto al "efecto invernadero" - o su equivalente, la necesidad de adquirir derechos internacionales de emisión- hasta nuevos espacios para los subsidios "verdes", los mecanismos de defensa comercial (salvaguardias y antidumping) o incluso la "igualdad de condiciones" en cuanto a las exigencias en materia de emisiones. Estas propuestas pueden afectar severamente el comercio internacional, al introducirse medidas orientadas a mantener la competitividad de las industrias nacionales respecto de las importaciones. ${ }^{11}$

\footnotetext{
${ }^{11}$ Para un examen de estas propuestas, véase CEPAL (2008a, cap. III).
}

La revisión de las iniciativas mencionadas revela una interesante paradoja. Las propuestas de los Estados Unidos, país que no ha suscrito el Protocolo de Kyoto, además de unilaterales, tienden a ser bastante más restrictivas que las de la Unión Europea, donde se privilegian más bien los subsidios ambientales y la readecuación del marco normativo de la omc a los desafíos del cambio climático. Si la región no se prepara adecuadamente para este debate y las eventuales negociaciones al respecto, podría llegar tarde nuevamente y al cabo de pocos años tendría que adecuarse a la aplicación de normas globales que no consideran sus intereses, enfrentando estándares energéticos y ambientales que limitarán sus avances en materia de competitividad.

\section{Un espacio para la cooperación regional}

La agenda internacional exige una mayor cooperación entre los países de América Latina y el Caribe a fin de mejorar su inserción en la economía mundial. Ello no solo se refiere a la necesidad de concordar mecanismos regionales que permitan mitigar los efectos de la crisis financiera internacional. También es apremiante para abordar los desafíos de competitividad e innovación, sin duda más influyentes, a mediano y largo plazo, en las condiciones de vida de las mayorías latinoamericanas y caribeñas (CEPAL 2008b).

En los temas antes considerados, esto es, seguridad, buenas prácticas, estándares privados de calidad y cambio climático es posible encontrar desvíos proteccionistas o al menos un espacio para ellos. Por eso es importante que América Latina y el Caribe vayan abordando estos aspectos en las instancias regionales y aumentando su preparación técnica e institucional, para adoptar enfoques comunes sobre cuestiones de creciente relevancia en el comercio internacional.

La seguridad en el comercio es un ámbito adecuado para concertar esfuerzos regionales en materia de facilitación y ayuda al comercio, estableciendo sinergias entre los gobiernos y las organizaciones empresariales de la región y compartiendo información tanto respecto de terceros mercados como de los pasos que se van dando en cada país, a fin de coordinar posturas al respecto. Por ejemplo, los acuerdos de reconocimiento mutuo con los principales socios comerciales pueden abordarse de un modo más coordinado, ya que si la región logra aunar los estándares y concretar una red de acuerdos internos sobre el tema, podría mejorar su posición negociadora frente a sus socios principales e impulsar al mismo tiempo el comercio intrarregional.

Los gobiernos de la región también podrían compartir información sobre las principales restricciones 
que enfrentan sus productos en los mercados industrializados debido a la aplicación de normas privadas que terminan incidiendo en la competitividad. Ello conduciría a negociaciones conjuntas con los gobiernos o agrupaciones privadas de esos países o a proyectos subregionales de facilitación del comercio que permitan adecuarse a las tendencias más consolidadas del escenario internacional.

En este sentido, la integración regional es necesaria y apremiante. A las razones tradicionales que la justifican se agregan las exigencias derivadas de la actual fase de globalización, tales como la necesidad de crear alianzas internacionales estratégicas en materia de planes de producción, logística, comercialización, innovación y tecnología. Los requisitos de competitividad e innovación tecnológica se acrecientan, en tanto el desarrollo acelerado de China, la India y otros países de Asia redefine drásticamente el mapa mundial del intercambio tanto de bienes y servicios como de capitales y ventajas comparativas. Los mercados ampliados, la certidumbre jurídica y la afinidad de normas y conectividad son hoy día indispensables para crecer con equidad. En fin, la convergencia entre los esquemas de integración es un elemento clave para un renovado regionalismo abierto de América Latina y el Caribe (CEPAL 1992, 1994, 2006a, 2006b y 2008a).

\section{IV}

\section{El surgimiento de nuevos competidores: los BRIC}

Uno de los rasgos más destacados de la economía mundial en la primera década del siglo XXI es la presencia consolidada de varias economías en desarrollo entre las figuras relevantes del escenario internacional. Lo más interesante, sin duda, ha sido el surgimiento de China como un actor global y de Asia como el continente que ha alcanzado el ritmo de crecimiento más elevado en la historia de la Humanidad. Quien mejor refleja esta situación es Larry Summers, en la introducción al excelente libro de Mahbubani que grafica el desplazamiento del poder en dirección al Asia. ${ }^{12}$

\section{La importancia de China en la economía mundial}

La evolución económica de China ha sido espectacular: en el período 1980-2008 creció a una tasa media anual del 9,9\%, bastante superior al 2,8\% logrado por América Latina y el Caribe. Como consecuencia de ello, el PIB chino es el segundo en importancia después del estadounidense,

\footnotetext{
${ }^{12}$ La llamaron Revolución Industrial, porque por primera vez en la historia de la Humanidad el estándar de vida mejoró a un ritmo suficientemente rápido como para observar los cambios —equivalentes tal vez al 50\% - en el espacio de una vida humana. A las actuales tasas de crecimiento, el estándar de vida asiático podría elevarse 100 veces, un $10.000 \%$ dentro de una vida humana. El surgimiento de Asia y todo lo que venga ocupará un lugar destacado en los libros de historia que se escriban al cabo de 300 años, dejando en segundo plano a la guerra fría y el ascenso del Islam (Mahbubani, 2008, p. 10).
}

en paridad de poder adquisitivo, y el tercero después de los Estados Unidos y el Japón, medido en dólares corrientes. Cualquier indicador internacional relevante recoge esta presencia creciente de China en los agregados globales, que ha dado lugar a un nuevo escenario en que Asia-Pacífico articula sus cadenas productivas en torno a China y este país profundiza activamente su intercambio con África y América Latina y el Caribe. En ese contexto, las economías asiáticas poseen el $60 \%$ del total mundial de reservas internacionales y el 53\% de los bonos del Tesoro estadounidense, contribuyendo con sus amplios superávits en cuenta corriente a la estabilidad de la economía global. Se ubican así en el centro de un próspero comercio Sur-Sur que representa el $41 \%$ del comercio total de los países en desarrollo (CEPAL, 2008c).

$\mathrm{Al}$ examinar los cambios en la clasificación mundial de exportadores, destaca el impresionante salto competitivo de China, cuya importancia aumentó desde el undécimo lugar en 1995 al segundo en 2007 (y al primero en 2008, según cifras por confirmar). Un repunte similar se aprecia en las exportaciones de manufacturas y de servicios (véase el cuadro 2).

El surgimiento de China como actor global cada vez más relevante se potencia debido a su capacidad de establecer alianzas con otras economías emergentes, tanto en materia de comercio (G-20, grupo agrícola de países en desarrollo articulados por Brasil en la Ronda de Doha) como de finanzas (presencia en el otro G-20, instancia que definiría los lineamientos básicos de la 
Países seleccionados: cambios en la clasificación mundial de exportadores

(Lugar que ocupan en la clasificación)

\begin{tabular}{|c|c|c|c|c|c|c|c|c|}
\hline & \multicolumn{2}{|c|}{ Bienes y servicios } & \multicolumn{2}{|c|}{ Bienes } & \multicolumn{2}{|c|}{ Manufacturas } & \multicolumn{2}{|c|}{ Servicios } \\
\hline & 1995 & 2007 & 1995 & 2007 & 1995 & 2006 & 1995 & 2007 \\
\hline Estados Unidos & 1 & 1 & 1 & 3 & 1 & 3 & 1 & 1 \\
\hline China & 11 & 3 & 9 & 2 & 9 & 2 & 8 & 5 \\
\hline Alemania & 2 & 2 & 2 & 1 & 2 & 1 & 3 & 3 \\
\hline Japón & 3 & 4 & 3 & 4 & 3 & 4 & 5 & 6 \\
\hline
\end{tabular}

Fuente: Comisión Económica para América Latina y el Caribe (CEPAL), sobre la base de cifras oficiales de la Organización Mundial del Comercio (OMC).

reforma del sistema financiero internacional). Lo anterior se difundió en forma más generalizada gracias al estudio de Goldman Sachs (2003), que dio origen al concepto de países BRIC. ${ }^{13}$

La notable expansión de China ya es conocida, pero lo interesante de este trabajo es que aporta información sobre la evolución de los restantes BRIC, proyectando no solo que en 2043 el PIB chino sobrepasaría al estadounidense, sino también que en 2040 los países de la Unión Europea dejarían de pertenecer al grupo de las principales economías industrializadas del mundo (G-8), siendo desplazados por China, la India y Brasil. Véase cuadro 3.

Más del $40 \%$ de la expansión dorada de la economía mundial en el ciclo 2003-2007 obedeció al crecimiento de los BRIC, cifra que podría elevarse al 70\% en 2009 dada la recesión en las economías centrales. De hecho, fue gracias al dinamismo de las economías emergentes —ámbito en que los países BRIC son una variable claveque la economía mundial no estuvo en recesión en 2008. Las economías BRIC fueron responsables de la mayor bonanza de inversión en la historia ${ }^{14}$ y con ello del alza de precios de la energía y los productos básicos que se vivió hasta septiembre de 2008, previo a la quiebra de Lehman Brothers y a que la crisis subprime se convirtiera en una crisis financiera global.

La presencia exportadora de los BRIC, que hace una década representaba el $7 \%$ del total mundial de exporta-

\footnotetext{
${ }^{13}$ En estos países se concentra el $43 \%$ de la población mundial, el $27 \%$ del PIB mundial, el $11 \%$ de las exportaciones mundiales de bienes y servicios y el $16 \%$ de las corrientes globales de inversión extranjera directa (Fitzgerald, 2007).

${ }^{14}$ En los tres últimos años, cerca de la mitad de la inversión mundial en infraestructura se habría realizado en las economías emergentes, que habrían asignado un 6\% del PIB a las inversiones en caminos, electricidad, vías ferroviarias y telecomunicaciones. Esta tasa de inversión respecto del producto duplica con creces la de las naciones industrializadas. Cabe destacar que China, en cinco años, habría invertido más (en términos reales) que en todo el siglo XX (The Economist, 2008b).
}

CUADRO 3

Clasificación de las principales economías
del mundo, 2000-2040

(Ordenadas según tamaño del PIB)

\begin{tabular}{|c|c|c|c|c|}
\hline & 2000 & 2020 & 2030 & 2040 \\
\hline 1 & E. Unidos & E. Unidos & E. Unidos & E. Unidos \\
\hline 2 & Japón & China & China & China \\
\hline 3 & Alemania & Japón & Japón & India \\
\hline 4 & R. Unido & Alemania & India & Japón \\
\hline 5 & Francia & R. Unido & Fed. de Rusia & Fed. de Rusia \\
\hline 6 & Italia & India & Alemania & Brasil \\
\hline
\end{tabular}

Fuente: elaboración propia sobre la base de información contenida en Goldman Sachs (2003), "Dreaming with brics: the path to 2050", Global Economics Paper, No 99, Nueva York, octubre de 2003.

ciones de bienes y el 3\% de servicios, aumentó en 2006 al $13 \%$ y el $8 \%$, respectivamente (véanse los gráficos 1 y 2). En 2007, los países BRIC acumulaban el $38 \%$ del total de reservas internacionales (véase el gráfico 3), en tanto China (21,3\%), la Federación de Rusia, Arabia Saudita, Kuwait, los Emiratos Árabes Unidos y Singapur generaron casi el $40 \%$ de los ahorros mundiales (véase el gráfico 4), la mitad de los cuales se utilizó para financiar el desahorro estadounidense. Estas cifras no solo indican la magnitud de los temas que es necesario abordar en la reforma del sistema financiero internacional, sino también el hecho de que cualquier solución sustentable a largo plazo deberá concederle un mayor espacio en la gobernabilidad financiera mundial a los BRIC y a las economías emergentes (Rosales, 2008).

\section{Los BRIC y el enfoque centro-periferia a comienzos del siglo XXI}

Según este difundido enfoque, la economía mundial comprendería dos grandes polos que interactúan: centro y periferia. Su estructura productiva es disímil, puesto que 
GRÁFICO 1

Países BRIC: participación en las exportaciones mundiales de bienes (En porcentajes)

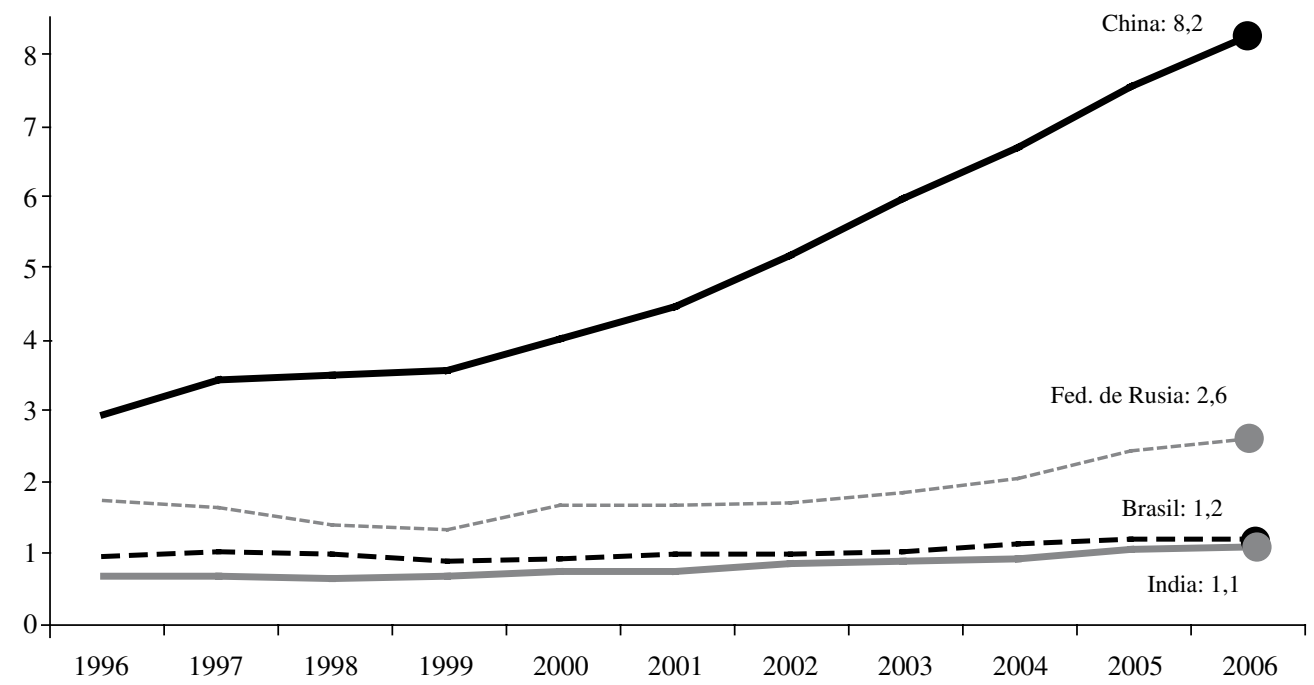

Fuente: base de datos estadísticos sobre el comercio de mercaderías (COMTRADE).

GRÁFICO 2

Países BRIC: participación en las exportaciones mundiales de servicios (En porcentajes)

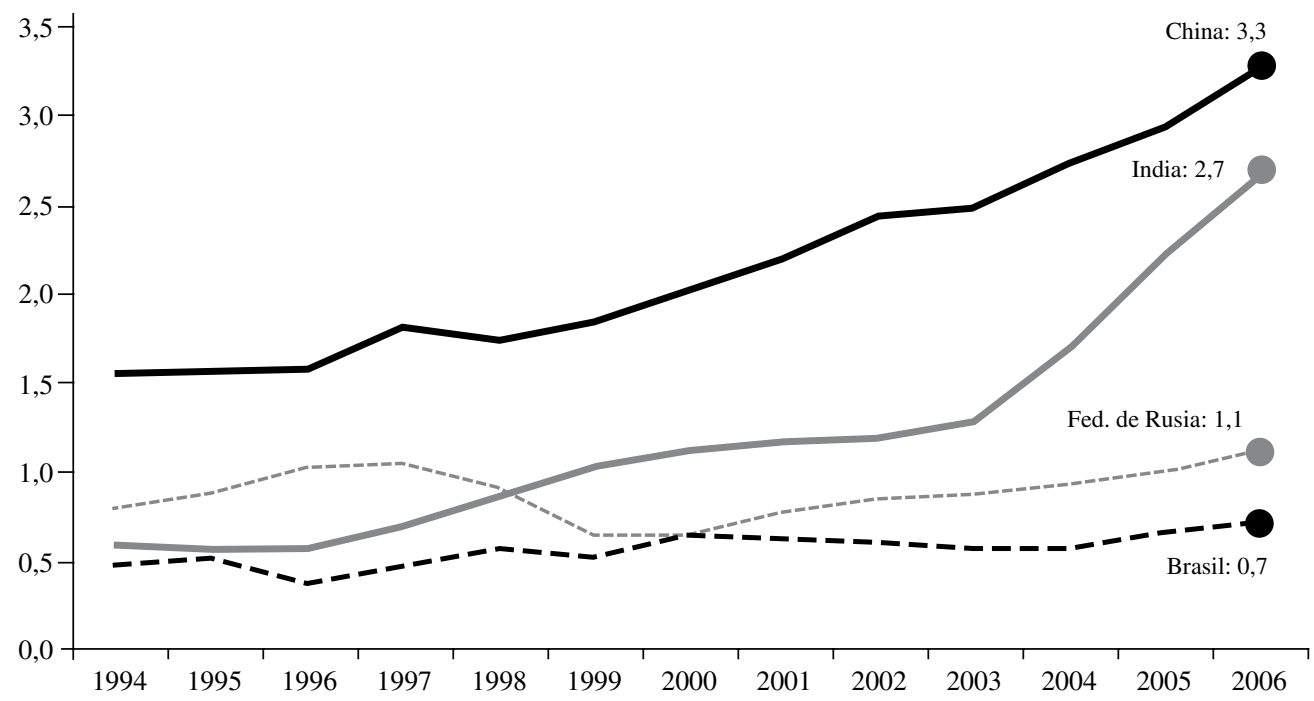

Fuente: Comisión Económica para América Latina y el Caribe (CEPAL) sobre la base de datos de la Organización de Cooperación y Desarrollo Económicos (OCDE).

mientras en la periferia sería heterogénea y especializada, en el centro sería homogénea y diversificada. De estas diferencias dependería el tipo de intercambio comercial y la transferencia tecnológica en la economía mundial. A largo plazo, la evolución económica de este sistema conduciría a un rezago productivo y tecnológico en la periferia y a un deterioro de sus términos de intercambio (Rodríguez, 1980). ${ }^{15}$

\footnotetext{
${ }^{15}$ Lo anterior ocurriría porque el amplio sector productor de bienes de capital de las economías centrales les permite acceder al progreso tecnológico, en tanto las ventajas de este se difunden en toda la
} 
GRÁFICO 3

Países BRIC: reservas internacionales

(En porcentajes del total mundial)

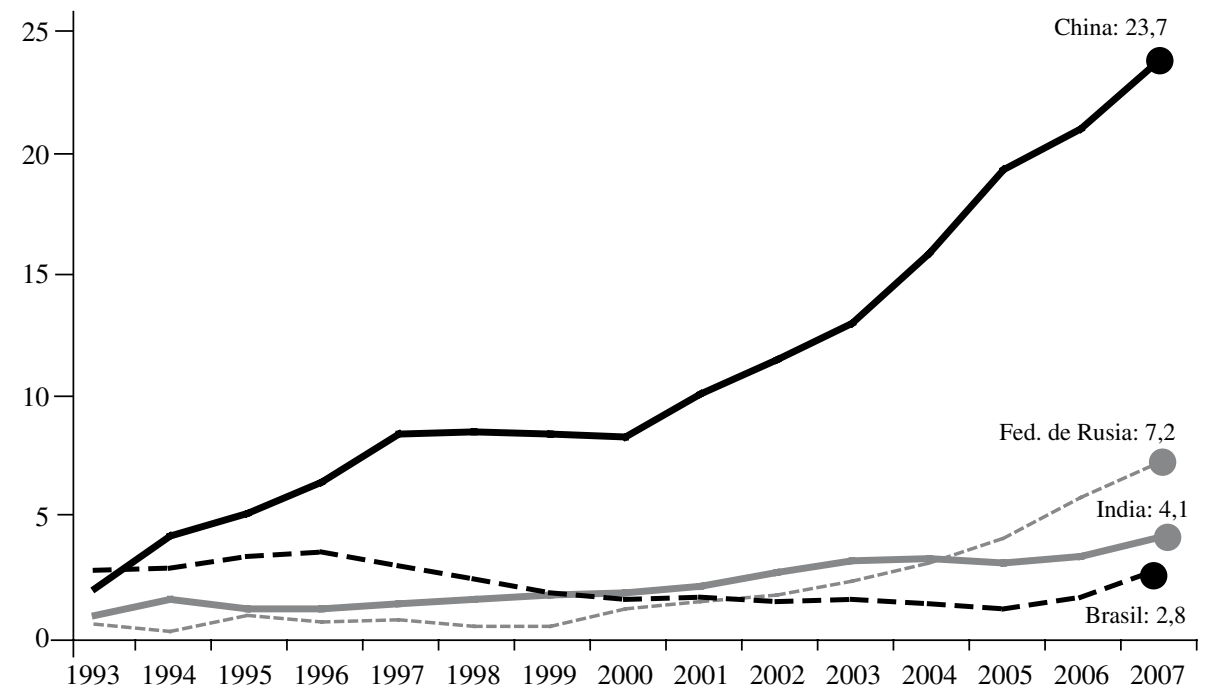

Fuente: Comisión Económica para América Latina y el Caribe (CEPAL), sobre la base de datos del Fondo Monetario Internacional (FMI).

GRÁFICO 4

Estructura del ahorro mundial, 2007

(En porcentajes del total ${ }^{a}$ )

EXPORTADORES DE CAPITAL (AHORRO)

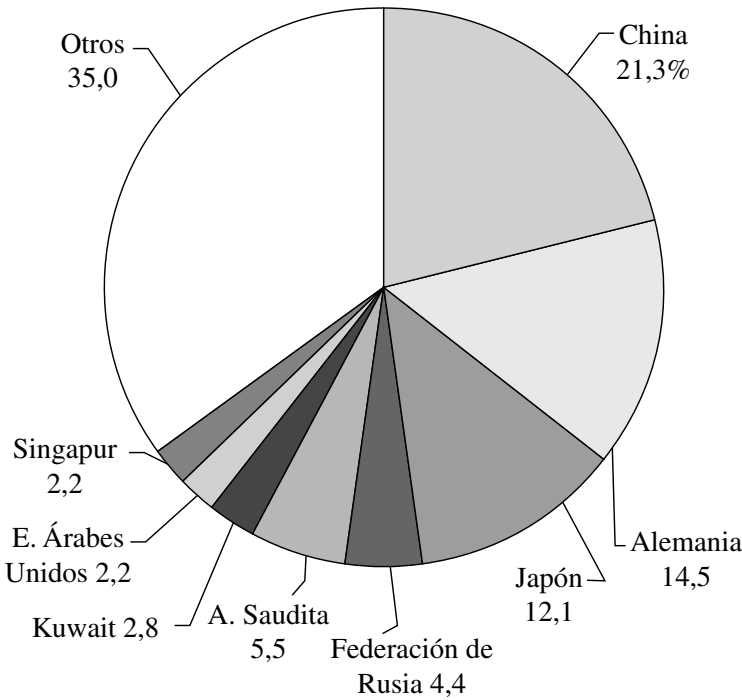

IMPORTADORES DE CAPITAL (DESAHORRO)

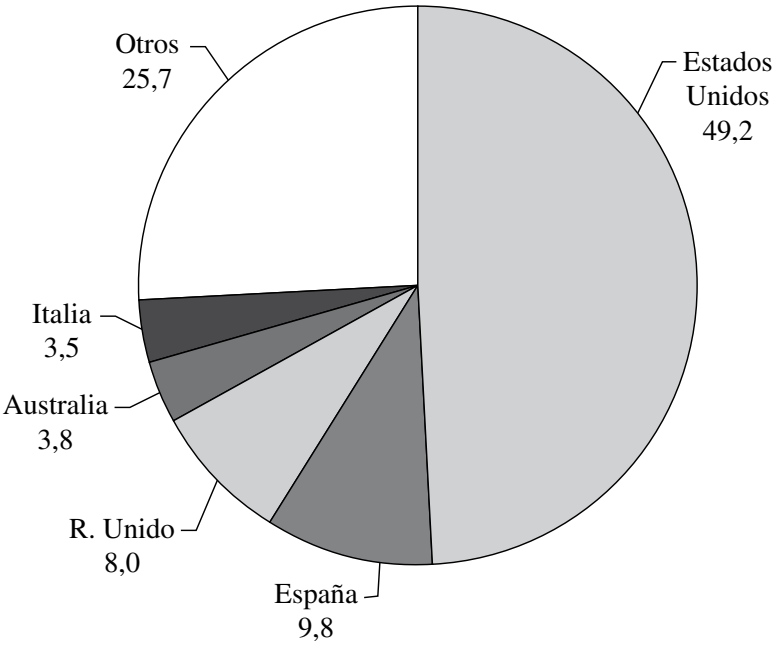

Fuente: Fondo Monetario Internacional (FMI), World Economic Outlook Database, octubre de 2008.

a Medidos según el saldo en cuenta corriente de la balanza de pagos de los países. 
Más allá del atractivo holístico de esta interpretación, está claro que la aplicación del enfoque "centro-periferia" no permite dar cuenta de las realidades actuales del comercio internacional. Por de pronto, la experiencia de China y varias economías asiáticas demuestra que la convergencia con los niveles de ingreso de las economías centrales, si bien lenta, es posible. Sin embargo, podría discutirse que esta aproximación ha sido posible justamente porque dichas economías desafiaron el patrón primario-exportador, incursionando en la exportación de manufacturas y avanzando gradualmente en el contenido tecnológico de las mismas. De hecho, las economías "periféricas" han sido capaces de acercarse en varios rubros a la frontera tecnológica, logrando ocupar un lugar de importancia en la economía mundial como exportadores de manufacturas, servicios o determinadas tecnologías.

Si se acepta el argumento anterior, entonces un primer paso sería incorporar en el análisis el hecho de que en la periferia hay dos subgrupos: uno tradicional y otro innovador, capaz de competir con éxito en las batallas globales de la economía del conocimiento. Lo siguiente sería indagar sobre las modalidades que pueden adoptar los vínculos entre ambos subgrupos de la periferia, esto es, si existe la posibilidad de que las relaciones intraperiféricas también sean marginadoras para las economías de la periferia que aún no emigran de la exportación de recursos naturales. Esta inquietud teórica tiene gran importancia en una etapa en que se están estrechando significativamente los vínculos económicos y comerciales entre China y América Latina (Rosales y Kuwayama, 2007), en que el comercio Sur-Sur se ha convertido en el motor de la economía mundial y donde las perspectivas de crecimiento de la economía china son cada vez más relevantes para buena parte de las economías latinoamericanas. ${ }^{16}$

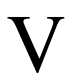

\section{Hacia una estrategia de internacionalización}

El contexto de la economía global de fines de la primera década del siglo XXI se caracteriza por la intensidad del cambio tecnológico, el surgimiento de nuevos y agresivos competidores globales y su correlato de cambios marcados en la competitividad y amenazas proteccionistas. Los sectores más vinculados a los recursos naturales o al trabajo de bajo nivel de calificación se expondrán en forma creciente a las modalidades tradicionales y renovadas de proteccionismo, lo que afectará de manera significativa las actividades productivas y de comercio exterior. Los países que capten más rápidamente esta situación y apliquen políticas adecuadas para enfrentarla, tenderán a ser más exitosos en sus esfuerzos de inserción internacional. ${ }^{17}$

\section{El contexto global}

En los próximos años, asistiremos a una aceleración de las innovaciones científicas y el cambio tecnológico, impulsada por los avances en materia de informática,

economía gracias a la presencia de sociedades más integradas y al mayor poder de los sindicatos. En la periferia, en cambio, las nuevas tecnologías son básicamente importadas debido a la ausencia o carácter marginal de la producción de bienes de capital, confinada además al sector exportador, que a su vez se limita al sector primario. Con ello, el excedente de trabajo mantiene salarios bajos, lo que impide tecnologías de la información y de las comunicaciones, biotecnología, nanotecnologías y neurociencias o ciencias cognitivas (Kelly, 2006). En efecto, la confluencia de aumento de la capacidad de procesamiento de los computadores, mayor velocidad y eficacia de la banda ancha, desarrollo de las tecnologías satelitales y del Sistema Mundial de Determinación de la Posición (GPS); tecnologías inalámbricas, perfeccionamiento de los sensores que reaccionan ante el calor, la torsión, la vibración y la tensión en el ámbito de la robótica, nuevos materiales y ciencias del cerebro ha conducido incluso al surgimiento de nuevos campos del conocimiento. ${ }^{18}$ Estos cambios son de por sí radicales, pero

que la periferia retenga los frutos de su limitado avance técnico. Así, el incremento de la productividad en el sector primario-exportador termina por transferirse al centro vía deterioro de los términos de intercambio.

${ }_{16}$ Para una completa reseña de las relaciones económicas y comerciales entre América Latina y China, véase CEPAL (2008c), cuya versión electrónica está disponible en www.cepal.org/comercio.

${ }^{17}$ En palabras del Primer Ministro de Singapur, siendo un país pequeño y sin recursos naturales, desde hace mucho tiempo sabemos que nuestra única posibilidad de competir es hacer del conocimiento una ventaja competitiva (Lee, 2008).

18 Entre otros, la bioinformática (aplicación de principios y procesos biológicos para desarrollar nuevas tecnologías tales como programas informáticos biológicos o informática ADN), la proteómica (estudio de la combinación de proteínas para curar enfermedades) y la biomímica (tecnologías que reproducen la actividad biológica) (Kelly, 2006). 
lo más novedoso es la creciente velocidad con que los nuevos conocimientos se aplican a la producción y las exportaciones, acortando el ciclo del producto y de las estrategias empresariales.

Esta convergencia tecnológica será más profunda que la digital que hemos vivido en los últimos 25 años, alterando radicalmente las perspectivas de la civilización y, por cierto, afectando en forma considerable la producción y el comercio internacional. La explosividad de esta confluencia de innovaciones tecnológicas queda bien reflejada mediante la expresión "big bang tecnológico". 19

Un breve examen de los efectos de esta sinergia de innovaciones en la estructura productiva revela, como es natural, la importancia de la innovación como eje articulador de las políticas orientadas a mejorar la competitividad. En el ámbito de la producción, destacan la digitalización de los procesos, los códigos de barra, la subcontratación externa (outsourcing) e interna (insourcing), la producción externalizada (offshoring), la conexión en línea, el intercambio de información compartida con proveedores y distribuidores y la innovación en línea, procesos que a su vez exigen una infraestructura de conexión o conectividad permanente, la articulación de redes globales y respuestas rápidas y oportunas (Friedman, 2006). Los procesos descritos no solo afectan la producción, sino también los campos de logística, transporte, seguridad y rastreabilidad de los bienes y, por ende, los espacios del comercio internacional.

De este modo, los cambios tecnológicos, conjuntamente con la liberalización de los movimientos financieros y la apertura gradual de los mercados al comercio y las inversiones, han acentuado la dinámica de la innovación, la convergencia de estándares internacionales y estrategias empresariales y la tendencia a organizar la producción en torno a redes globales de valor (OCDE, 2005 y 2008). Estas últimas dan lugar a una fragmentación geográfica de los procesos productivos, aprovechando la digitalización creciente de muchas actividades, la mayor internacionalización y comercialización de los servicios y la reducción de los costos de transporte y logística. Ello estimula además la especialización, la innovación en actividades seleccionadas y la creación de nuevas empresas y oficios. La internacionalización de los servicios y la explosión de la subcontratación de los mismos han favorecido la generación de una oferta

\footnotetext{
${ }^{19}$ El término bang sería la combinación de bits (tecnologías de la información), átomos (nanotecnologías), neuronas (ciencias cognitivas) y genes (biotecnologías).
}

global de actividades calificadas de diseño, consultoría y fabricación de insumos específicos. Esto permite el surgimiento de empresas nuevas, internacionalmente competitivas en cuanto a la provisión de servicios estratégicos y evita la necesidad de realizar grandes inversiones en infraestructura global para acceder a los mercados mundiales o en el aprendizaje de complejas técnicas empresariales (Hamel, 2008).

Las cadenas globales de valor abarcan desde la investigación y desarrollo hasta el reciclaje del producto, pasando por la producción, los servicios de apoyo, la distribución, la comercialización, las finanzas y los servicios de posventa. El objetivo de estas cadenas es aumentar el contenido de conocimientos en cada una de sus etapas, ya que en ello radica el valor por unidad producida. En el debate actual sobre la competitividad aumenta entonces la importancia de los aspectos "intangibles" que más contribuyen a la intensidad de conocimientos de cada segmento de la cadena global de valor, esto es, calidad, oportunidad, conectividad, patentabilidad y registro de marcas, rastreabilidad, inocuidad, conservación ambiental y eficiencia energética. Todos estos atributos son los que posibilitan la diferenciación de los productos y, con ello, el acceso a los sectores más lucrativos de la demanda y una vinculación más funcional con las tendencias del cambio tecnológico y de la demanda internacional.

\section{Algunas orientaciones de política}

Se sugiere aquí que el objetivo de las políticas orientadas a mejorar la inserción de los países de América Latina y el Caribe en la economía internacional no puede medirse solamente mediante la participación de las exportaciones en el PIB, sino que también es necesario prestar atención a la composición de estas (privilegiando su contenido de conocimientos), así como al modo de integración con el resto del sistema productivo y su incidencia en la homogeneización progresiva de los niveles de productividad de la economía. En efecto, hoy día existe la posibilidad de invertir la conocida "heterogeneidad estructural" de la región, en la medida en que las políticas públicas se orienten decididamente a aprovechar el acceso a las nuevas tecnologías para reducir la brecha de productividad entre empresas y sectores. Sin esfuerzos sustantivos en esta dirección, el nivel de heterogeneidad tecnológica tenderá a acentuarse, haciendo cada vez más inviable conciliar el crecimiento con los avances en materia de equidad. Además, cabe señalar que las políticas de inserción internacional deben concederle mayor espacio a las medidas que favorecen la internacionalización de 
las empresas y de sus contactos, pues en ello radican las posibilidades de lograr un crecimiento más elevado y mejorar el acceso a las fuentes de innovación.

a) De la apertura comercial y la orientación exportadora a las estrategias de internacionalización

Las políticas de inserción internacional han evolucionado desde la apertura comercial en la década de 1980 hasta la orientación exportadora. Sin embargo, el surgimiento de cadenas globales de valor y el creciente peso de la innovación en las actividades productivas y de comercio exterior exigen ahora un paso adicional: la aplicación de políticas orientadas explícitamente a la internacionalización, incluidas la formación de recursos humanos calificados, el estímulo de las aglomeraciones productivas (clusters), los programas de innovación y la atracción de inversión extranjera directa (IED), portadora de tecnología y conocimientos hacia sectores o actividades específicos. Solo así será posible captar cuotas significativas de los mercados internacionales relevantes y mantener un ritmo de innovación que permita conservar las posiciones competitivas conquistadas.

Las estrategias de internacionalización deben favorecer la creación de alianzas y redes internacionales en diversos ámbitos, a fin de que las actividades productivas nacionales insertas en las cadenas globales de valor puedan ascender de jerarquía hasta ubicarse en sus eslabones más rentables, mediante un conjunto de inversiones que contribuya a elevar su contenido de conocimiento. Ello significa, por ejemplo, reforzar los vínculos entre el comercio de bienes y servicios y las inversiones, situar la innovación en el centro de las políticas de competitividad y apoyarse en alianzas público-privadas que la estimulen. Estas harían más factible avanzar en la adopción de modalidades de producción que permitan: reforzar los eslabonamientos entre actividades primarias, manufacturas y servicios; diversificar la base productiva y exportadora; y aumentar la presencia directa o indirecta de las pymes en esa dinámica exportadora, procurando favorecer una distribución más equilibrada del incremento de la productividad.

\section{b) De la inserción en el comercio internacional a la inserción en las cadenas mundiales de valor \\ Mientras que el objetivo anterior de las políticas de} inserción internacional pudo haber sido el de potenciar el comercio, debido a la importancia de la innovación tecnológica, en la actualidad es preciso favorecer la introducción de nuevas tecnologías y la inserción en las cadenas mundiales de valor. Ello significa, por ejemplo, que la política comercial — centrada, en esta primera década del siglo XXI, en las negociaciones comerciales y la suscripción de acuerdos de libre comercio- debería orientarse hoy día a la administración de dichos acuerdos con una mirada estratégica. Para esos efectos, conviene concebirlos como un espacio de asociación con socios relevantes en los ámbitos de inversión y avance tecnológico, facilitando la creación de programas conjuntos conexos, así como la posibilidad de realizar inversiones conjuntas en los mercados vecinos. Se trata de utilizar los acuerdos comerciales como plataforma para atraer IED hacia los sectores de uso intensivo de tecnología y, por otra parte, para aumentar la presencia de las empresas nacionales en las redes internacionales de innovación, negocios tecnológicos y cadenas globales de valor. En síntesis, la política comercial debe ser un instrumento de la estrategia de inserción internacional en las redes de innovación y negocios tecnológicos.

i) Reemplazar la investigación y desarrollo por una corriente de innovación, inversión y marketing (de la $I+D$ a $l a ~ I+I+M)$. Lo anterior implica que en vez del concepto tradicional de investigación y desarrollo (I+D), debería adoptarse más bien un enfoque basado en una corriente continua de innovación, inversión y marketing $(\mathrm{I}+\mathrm{I}+\mathrm{M})$, es decir, de conocimiento que se vincula rápidamente con la inversión y la producción y se introduce en el mercado internacional mediante nuevos productos, procesos o estrategias. ${ }^{20}$ Para ello se requiere de una actitud más proactiva en materia de marcas y patentes, estimulando la obtención y exportación de patentes y, por medio de ellas, de conocimientos. La estructura de incentivos debería recoger esta orientación, a fin de que la comunidad científica perciba que la recompensa será mayor con una patente que con un estudio académico. Asimismo, una relación más estrecha entre empresas, universidades y centros tecnológicos permitiría ir desarrollando la noción de "negocio tecnológico", que favorece a todos los participantes de esa alianza, en comparación con el concepto actual de "proyecto de investigación" financiado con fondos públicos y cuyas vinculaciones con la actividad productiva — cuando las hay — son bastante débiles.

ii) Privilegiar la innovación e incorporarla en la agenda empresarial. La innovación se ha convertido en el eje central de las estrategias exitosas de inserción internacional. Es un concepto más amplio que el de investigación y desarrollo tradicional. Incluye desde

\footnotetext{
${ }^{20}$ Debo esta expresión de I+I+M a Ángel Flisfisch, ex embajador de Chile en Singapur, quien la utilizó en unas notas a la Dirección General de Relaciones Económicas Internacionales del Ministerio de Relaciones Exteriores alrededor del año 2002.
} 
la copia y la adaptación tecnológica hasta la investigación en materia de productos y procesos, los nuevos modelos de negocios y las actividades de marketing, financiamiento y logística que conducen a la creación de nuevo valor realizable — de preferencia en el mercado internacional - por medio de diversas modalidades de diferenciación de marca, esto es, "descomoditizando" los productos o servicios.

En el caso de la región, correspondería dar prioridad a la innovación en las empresas procesadoras de recursos naturales, aunque sin renunciar a ella en industrias nuevas relacionadas especialmente con la biotecnología y las tecnologías de la información y de las comunicaciones. No existe una "muralla china" entre este tipo de actividades. Al contrario, la biotecnología es la base del nuevo conocimiento, representa gran parte del valor agregado a los recursos naturales y permite la comercialización de nuevos productos de la agroindustria, el sector forestal, la acuicultura y la minería.

Por otra parte, el tema de la innovación debería ocupar un lugar más relevante en la agenda empresarial. Para esos efectos, sería preciso aplicar políticas públicas orientadas a apoyar a las organizaciones de pequeñas y medianas empresas - por ejemplo, mediante el financiamiento de horas de trabajo de profesionales especializados en el tema-, a fin de favorecer la colaboración conjunta de las pymes en torno a diversas tareas de innovación. También convendría que las organizaciones empresariales más destacadas designaran representantes gremiales de innovación, inversión y marketing, definiendo programas de trabajo y de vinculación de sus asociados con universidades y centros tecnológicos nacionales e internacionales. Al respecto, hace falta una amplia gama de becas, memorias, pasantías y proyectos de investigación que vayan reforzando las relaciones del campo del saber con la producción y el comercio exterior.

iii) Reforzar el vínculo entre bienes, servicios e inversiones. Dada la incorporación creciente de los servicios a las cadenas de valor, estos se han convertido en el principal componente de valor agregado de los productos. Al respecto, destacan los servicios de consultoría, publicidad y marketing, asistencia legal, contabilidad y finanzas, tecnologías de la información y de las comunicaciones e ingeniería y control de calidad, entre otros. Gracias a la difusión de las nuevas tecnologías, las ventajas competitivas tienden a expresarse ahora en "redes internacionales de valor". En los primeros lugares de los encadenamientos se encuentran los aspectos de uso intensivo de "conocimiento", tales como marcas, patentes, calidad y derechos de autor, mientras que en los inferiores se ubican las actividades de uso más intensivo de recursos naturales, menor grado de elaboración y que utilizan mano de obra menos calificada. En este sentido, el acceso masivo de las empresas, particularmente de las pymes, a los servicios modernos es un factor decisivo para estimular el incremento de la productividad.

No es realista, por lo tanto, separar la competitividad en materia de bienes de la posibilidad de contar oportunamente con servicios de calidad internacional y a precios competitivos o de acceder a tecnologías modernas de productos, procesos o gestión, que por lo general se encuentran incorporadas a la inversión extranjera directa. Las políticas públicas deben facilitar el acceso a estos servicios a un nivel de costos y calidad comparables con los estándares internacionales, así como promover la exportación de los servicios empresariales en que el país tenga o pueda construir ventajas competitivas (ingenierías, arquitectura, consultorías, construcción, comunicaciones, diseño, técnicas audiovisuales, salud y otros). ${ }^{21}$

iv) Incluir la inversión en el exterior entre los objetivos de las políticas públicas. Las inversiones en el exterior siguen el propio ciclo de internacionalización de las empresas, una vez que estas han incursionado con algún grado de éxito en los mercados internacionales. $\mathrm{Al}$ exportar bienes y servicios en forma exitosa, se comprueba rápidamente que el retorno de los diversos elementos de la cadena de valor vinculados a un producto determinado - producción, logística, transporte, distribución, marketing — varía en función de la intensidad de conocimientos que caracteriza a cada segmento de esa cadena. Por lo tanto, el próximo paso en la evolución natural de las actividades exportadoras, sobre todo de aquellas de uso intensivo de recursos naturales, es aumentar directa o indirectamente la presencia relativa en las cadenas de valor por medio de alianzas con importadores y distribuidores en los mercados de destino. Por ejemplo, la consolidación de las exportaciones manufactureras del Brasil en la región ha conducido a una amplia expansión de la exportación de servicios brasileños hacia diversos mercados externos en seguimiento de los clientes internos. Ello se ha detectado, entre otros, en el ámbito de los servicios financieros, legales y de construcción (CNI, 2007).

El objetivo de las inversiones en el exterior, entonces, sería conseguir una mayor presencia en las redes globales de valor vinculadas a los principales productos de exportación. Dado que la región continúa exportando

\footnotetext{
${ }^{21}$ En la región hay varios casos interesantes de exportación de este tipo de servicios. Véase, por ejemplo, CEPAL (2007).
} 
básicamente recursos naturales, se trata de seguir los eslabonamientos hacia atrás y hacia adelante del recurso natural exportado, desarrollando ventajas competitivas en el ámbito de la ingeniería, la biotecnología y los servicios empresariales conexos. Ello permitirá que los exportadores participen en otras redes de nuevos negocios, que actuén como antenas de la innovación tecnológica y empresarial en los principales mercados $y$, por último, que sirvan como plataforma de aprendizaje empresarial para realizar operaciones globales de mayor envergadura. Así, por ejemplo, el ingreso de las empresas procesadoras, proveedoras y comercializadoras de los países en desarrollo a las cadenas mundiales de valor no solo depende de la estrategia de las empresas transnacionales, sino también de las políticas proactivas de internacionalización que aplican las primeras. En este sentido, el fenómeno de las "translatinas" constituye un caso interesante de examinar, tanto para actualizar las políticas públicas de apoyo a la inserción internacional como para evaluar los esfuerzos de integración regional. ${ }^{22} \mathrm{Al}$ respecto, convendría que los mecanismos de integración fueran compatibles con la experiencia de las translatinas y otros casos exitosos de desarrollo empresarial.

v) Convertir la formación de recursos humanos en el eje central de la transformación productiva. Lograr la competitividad en sectores cuyo alcance supera el de un recurso natural de bajo grado de elaboración, exige la formación de una masa crítica de recursos humanos calificados que, unida a las ventajas comparativas naturales y a ciertas facilidades mínimas en materia de infraestructura y conectividad, permita atraer talentos nacionales y extranjeros para que participen en proyectos de interés global. Si bien es cierto que los países de América Latina y el Caribe no están en condiciones de formar esa masa crítica en el caso de la mayoría de los productos, pueden hacerlo para algunos. Esto implicaría, por ejemplo, promover el desarrollo de proveedores locales de insumos, partes y servicios especializados (diseño, control de calidad, logística, distribución) en los segmentos de la cadena de valor vinculados al recurso natural exportado de que se trate. Para ello sería necesario aplicar políticas públicas orientadas a asegurar que los productores internos puedan cumplir con los estándares internacionales pertinentes. Sobre esa base, es posible formar recursos humanos calificados en ámbitos donde

\footnotetext{
${ }^{22}$ En efecto, si hay un objetivo integracionista relevante que no se ha cumplido es justamente el de construir cadenas productivas regionales que favorezcan la competencia en los mercados internacionales.
}

el país disponga de ventajas competitivas o pueda construirlas, complementándolas con apoyos específicos del gobierno central o regional en actividades de educación y capacitación, además de infraestructura y logística. Esta modalidad ha demostrado su relevancia en varios países latinoamericanos, permitiendo atraer inversión extranjera directa hacia los sectores de uso intensivo de tecnología y adquirir presencia en la exportación de productos y servicios de calidad (informática y productos farmacéuticos en el caso de Costa Rica, biotecnología e informática en la Argentina e informática y logística en el Uruguay).

Esto no solo significa pensar en la creación de programas masivos de becas de doctorado, que forman parte de la estrategia adecuada, sino también en una reforma de los planes de educación media y universitaria, en proyectos especiales para potenciar los talentos, en programas nacionales de refuerzo escolar en matemáticas, inglés y ciencias básicas y en iniciativas públicas que reflejen el alto grado de compromiso de los gobiernos con el mejoramiento de calidad en materia de educación. ${ }^{23}$

vi) Privilegiar los aspectos intangibles de la competitividad. Las políticas de fomento productivo y de promoción de las exportaciones orientadas a mejorar la competitividad de las pymes deberían privilegiar el fortalecimiento de su capacidad tecnológica y gerencial, la capacitación del personal, el cumplimiento de las normativas internacionales de calidad, su mayor colaboración recíproca y su presencia en las redes globales de valor. Esto último incluye la posibilidad de considerar a este tipo de empresas como exportadores indirectos en las cadenas de valor internas relacionadas con la exportación de bienes y servicios.

vii) Fortalecer la coordinación interagencial y el enfoque integrado de las políticas. Avanzar en la orientación descrita exige mayor coordinación entre las diversas instituciones públicas vinculadas a las políticas de apoyo a la internacionalización, esto es, entre las agencias de promoción y diversificación de las exportaciones, de atracción de IED, de innovación y difusión tecnológica, de fomento productivo y empresarial y, por último, de capacitación y formación de recursos humanos, incluidas la educación media y universitaria.

Si bien es cierto que siempre hay algún grado de coordinación entre las agencias gubernamentales, lo

\footnotetext{
${ }^{23}$ Hace pocos años, en Malasia se decidió impartir la enseñanza de las matemáticas y las ciencias básicas en idioma inglés, en el entendido de que ello favorece la escolaridad de la población en el contexto de la economía global del conocimiento (Lee, 2008).
} 
que aquí se plantea es la necesidad de que funcionen en torno a planes compartidos en que se hayan expresado los distintos intereses territoriales y con responsabilidades bien definidas en materia de financiamiento, coordinación y desempeño. Esto es lo que se aprecia en las experiencias exitosas de inserción internacional, destacando en ellas el elevado grado de compromiso de las principales autoridades políticas.

viii) De las políticas públicas a las alianzas público-privadas. Por último, pero no menos importante, cabe señalar que los criterios sugeridos de política requieren de una alianza público-privada como marco institucional decisivo para avanzar en las tareas de innovación, competitividad e internacionalización.
Es en torno a esta alianza que será posible construir una visión de país para los próximos 10 o 20 años, de sus fortalezas y debilidades y de las tareas que le corresponderían al gobierno y a las organizaciones privadas, empresariales y laborales, respectivamente, para abordar conjuntamente los desafíos en materia de innovación y competitividad. Este diagnóstico de futuro compartido, con una mirada a mediano plazo que trasciende los ciclos políticos, facilita la definición de los compromisos, programas y necesidades de financiamiento que deberán afrontar los actores públicos y privados, así como un enfoque integrado de las políticas orientado a que la coordinación interagencial supere el plano meramente formal.

\section{Bibliografía}

Brewer, T. (2007), U.S. Climate Change Policies and International Trade Policies: Intersections and Implications for International Negotiations, Washington, D.C., Universidad de Georgetown, noviembre.

CEPAL (Comisión Económica para América Latina y el Caribe) (2008a), Panorama de la inserción internacional en América Latina y el Caribe, 2007. Tendencias 2008 (LC/G.2391-P), Santiago de Chile.

(2008b), "Crisis internacional y oportunidades para la cooperación regional" (LC/R.2150), Santiago de Chile, diciembre.

(2008c), "Las relaciones económicas y comerciales entre América Latina y el Asia-Pacífico. El vínculo con China", Segunda Cumbre Empresarial China-América Latina, Harbin, China, 20 y 21 de octubre.

(2007), Panorama de la inserción internacional de América Latina y el Caribe, 2006. Tendencias 2007 (LC/G.2341-P), Santiago de Chile. Publicación de las Naciones Unidas, $\mathrm{N}^{\mathbf{0}}$ de venta: S.07.II.G.85.

(2006), Panorama de la inserción internacional de América Latina y el Caribe, 2005-2006, (LC/G.2313-P), Santiago de Chile. Publicación de las Naciones Unidas, $\mathrm{N}^{\circ}$ de venta: S.06.II.G.67. (1994), "El regionalismo abierto en América Latina y el Caribe: la integración económica al servicio de la transformación productiva con equidad", Libros de la CEPAL, № 39 (LC/G.1801/ Rev.1-P), Santiago de Chile. Publicación de las Naciones Unidas, $\mathrm{N}^{\circ}$ de venta: S.94.II.G.3.

(1992), "Equidad y transformación productiva: un enfoque integrado", Libros de la CEPAL, No 32 (LC/G.1701/Rev.1-P), Santiago de Chile. Publicación de las Naciones Unidas, $\mathrm{N}^{\mathrm{o}}$ de venta: S.92.II.G.5.

CNI (Confederación Nacional de la Industria) (2007), "Os interesses empresariais brasileiros na América do Sul", Río de Janeiro.

Comisión de las Comunidades Europeas (2003), Comunicación de la Comisión del Consejo, el Parlamento Europeo, el Comité Económico y Social Europeo y el Comité de las Regiones: mejora de la protección del transporte marítimo (COM (2003) 229 final), Bruselas.

Fitzgerald, E. (2007), "Los nuevos colosos emergentes y su efecto sobre la economía internacional", Claves de la economía mundial, $\mathrm{N}^{\mathrm{o}}$ 7, Madrid, Instituto Español de Comercio Exterior.

FMI (Fondo Monetario Internacional) (2008), World Economic Outlook Database, octubre.
Friedman, T. (2006), La tierra es plana. Breve historia del mundo globalizado del siglo XXI, Madrid, Martínez Roca.

Goldman Sachs (2003), "Dreaming with BRICs: the path to 2050", Global Economics Paper, No 99, Nueva York, octubre.

Hamel, G. (2008), El futuro de la administración, Bogotá, D.C., Grupo Editorial Norma.

Hufbauer, G.C. (2008), "Climate change: competitiveness concerns and prospects for engaging developing countries", testimonio ante el Subcomité de Energía y Calidad del Aire de la Cámara de Representantes de los Estados Unidos.

Kelly, E. (2006), La década decisiva. Tres escenarios para el futuro del mundo, Bogotá, D.C., Grupo Editorial Norma.

Lee, H.L. (2008), "Speech by Prime Minister Lee Hsien Loong", Londres, London School of Economics, 11 de abril.

Mahbubani, K. (2008), The New Asian Hemisphere. The Irresistible Shift of Global Power to the East, Nueva York, Public Affairs.

OCDE (Organización de Cooperación y Desarrollo Económico) (2008), Staying Competitive in the Global Economy: Compendium of Studies on Global Value Chains, París.

(2005), Handbook on Economic Globalization Indicators, París.

OMC (Organización Mundial del Comercio) (2004), El futuro de la oMC. Una respuesta a los desafíos institucionales del nuevo milenio, Ginebra.

oms (Organización Mundial de la Salud) (2007), Informe sobre la salud en el mundo, 2007. Un porvenir más seguro: protección de la salud pública mundial en el siglo XXI, Ginebra.

Rodríguez, O. (1980), La teoría del subdesarrollo de la CEPAL, México, D.F., Siglo XXI Editores.

Rosales, O. (2008), "G20 Summit and the road ahead", China Daily, Beijing, 19 de noviembre.

Rosales, O. y M. Kuwayama (2007), "América Latina al encuentro de China e India: perspectivas y desafíos en comercio e inversión", Revista de la CEPAL, Nº 93 (LC/G.2347-P), Santiago de Chile.

Salles de Almeida, J. (2008), "Normas privadas: el nuevo desafío de las exportaciones de los países en desarrollo", serie Comercio internacional, $\mathrm{N}^{\circ} 85$ (LC/L.2861-P), Santiago de Chile, Comisión Económica para América Latina y el Caribe (CEPAL). Publicación de las Naciones Unidas, $\mathrm{N}^{\mathrm{o}}$ de venta: S.08.II.G.06.

The Economist (2008a), "Barriers to entry", 20 de diciembre. (2008b), "Building BRICS of Growth", 27 de junio. 